\title{
Opportunities and challenges in biological lignin valorization
}

Gregg T. Beckham, Christopher W. Johnson, Eric M. Karp, Davinia Salvachúa, Derek R. Vardon

National Bioenergy Center, National Renewable Energy Laboratory, Golden CO 80403 United States

Corresponding author: Gregg T. Beckham, Email: gregg.beckham@nrel.gov, Phone: +01-303-384-7806

Abstract: Lignin is a primary component of lignocellulosic biomass that is an underutilized feedstock in the growing biofuels industry. Despite the fact that lignin depolymerization has long been studied, the intrinsic heterogeneity of lignin typically leads to heterogeneous streams of aromatic compounds, which in turn present significant technical challenges when attempting to produce lignin-derived chemicals where purity is often a concern. In Nature, microorganisms often encounter this same problem during biomass turnover wherein powerful oxidative enzymes produce heterogeneous slates of aromatics compounds. Some microbes have evolved metabolic pathways to convert these aromatic species via "upper pathways" into central intermediates, which can then be funneled through "lower pathways" into central carbon metabolism in a process we dubbed "biological funneling". This funneling approach offers a direct, biological solution to overcome heterogeneity problems in lignin valorization for the modern biorefinery. Coupled to targeted separations and downstream chemical catalysis, this concept offers the ability to produce a wide range of molecules from lignin. This perspective describes research opportunities and challenges ahead for this new field of research, which holds significant promise towards a biorefinery concept wherein polysaccharides and lignin are treated as equally valuable feedstocks. In particular, we discuss tailoring the lignin substrate for microbial utilization, host selection for biological funneling, ligninolytic enzyme-microbe synergy, metabolic engineering, expanding substrate specificity for biological funneling, and process integration, each of which presents key challenges. Ultimately, for biological solutions to lignin valorization to be viable, multiple questions in each of these areas will need to be addressed, making biological lignin valorization a multidisciplinary, co-design problem.

Introduction. Lignin is an aromatic heteropolymer that provides terrestrial plants with strength and rigidity, facilitates water and nutrient transport in plant tissues, and forms a heterogeneous, recalcitrant barrier to microbial attack. Lignin biosynthesis occurs via oxidative coupling reactions starting from aromatic alcohols that differ in degree of methoxylation: $p$-coumaryl alcohol $(\mathrm{H})$, coniferyl alcohol (G), and sinapyl alcohol (S). In grasses and agricultural residues, hydroxycinnamic acids also form a significant amount of the available monolignols [1], thus enriching the heterogeneity of lignin. Recently, an additional natural monolignol, caffeoyl alcohol, was discovered in seed coats of several plant species [2], demonstrating that other naturally occurring lignins may remain to be discovered. Moreover, a substantial number of genetic modifications to lignin biosynthesis have been reported in the last several years, towards the aim of reducing biomass recalcitrance, with several prominent examples of either modifying the ratio of monolignols or redesigning chemical linkage types via expression of alternative monolignols [3-6].

Lignin valorization will be essential based on technoeconomic analyses of lignocellulosic biorefineries [7], but current plant designs slate lignin for combustion to produce heat and power. With pioneer cellulosic ethanol plants being commissioned around the world today, the lack of broad lignin conversion technologies will become more acute, especially considering that a typical bioethanol plant will likely produce roughly 70,000 tons per year of lignin based on a 2,000 ton per day plant using corn stover as a feedstock [7]. Lignin valorization has been studied for many decades with a variety of catalytic, thermal, and biological approaches to break it down to its constituent monomers and oligomers and upgrade the resulting monomers to fuels or chemicals [8-10]. With very few exceptions, most lignin depolymerization technologies provide a heterogeneous slate of aromatic species that depends on the feedstock and the approach used to break down the lignin as well as contaminating species from other biomass polymers. For fuels production, a heterogeneous mixture of aromatic species is often acceptable [8,9]. However, for chemicals production, where purity and high yields are of paramount importance, this heterogeneity of lignin poses a major challenge.

In Nature, lignin is primarily broken down via the action of peroxidases, laccases, and additional oxidative enzymes from fungi and bacteria [10]. These enzymes generate aromatic radicals that cleave diverse lignin linkages through non-enzymatic reactions [10], producing a large slate of oxygenated aromatics during the turnover of lignocellulose in the biosphere. As a result of this abundance of aromatic carbon, microbes have evolved various catabolic pathways and mechanisms to utilize aromatic species [11]. Aerobic bacteria employ "upper pathways" for converting broad slates of aromatic compounds into a few central intermediates, such as catechol and protocatechuate [11]. Subsequently, ringopening dioxygenases are able to cleave the aromatic rings either via intra- or extra-diol (ortho or meta) cleavage depending on the enzyme type expressed. The ring-cleavage products are enzymatically converted through "lower pathways" to central carbon metabolism, providing a carbon and energy source. A relatively unexplored field for biotechnology purposes to our knowledge is the aromatic catabolism of anaerobic bacteria. In this case, dearomatization proceeds using reductive $\mathrm{CoA}$ thioesters that destabilize the aromatic ring structure and lead to common intermediates such as benzoyl-CoA $[11,12]$. These intermediates can be further 
reduced by ATP-dependent (facultative anaerobes) or ATP-independent (obligate anaerobes) reductases to facilitate ring-opening and subsequent $\beta$-oxidation-like reactions to form central intermediates. As described below, we will mainly focus in aerobic catabolism in the current work.

Given the inherent heterogeneity of lignin, these upper pathways that funnel multiple species to one or two intermediates offer a potential biological solution for lignin valorization to chemicals. This topic has only recently gained traction in the lignin valorization community. As such, here we review the last several years of research in this topic and present our perspective on what the key challenges are going forward to harness microbial catabolism as a viable process for producing chemicals from lignin via a biological approach. We separate this problem into the lignin substrate, microbe selection, enzyme-microbe synergy, metabolic engineering and synthetic biology applications, and process integration with upstream and downstream unit operations (Figure 1). A recent review from Bugg et al. covers complementary aspects of this topic in enzyme applications in this area [13].

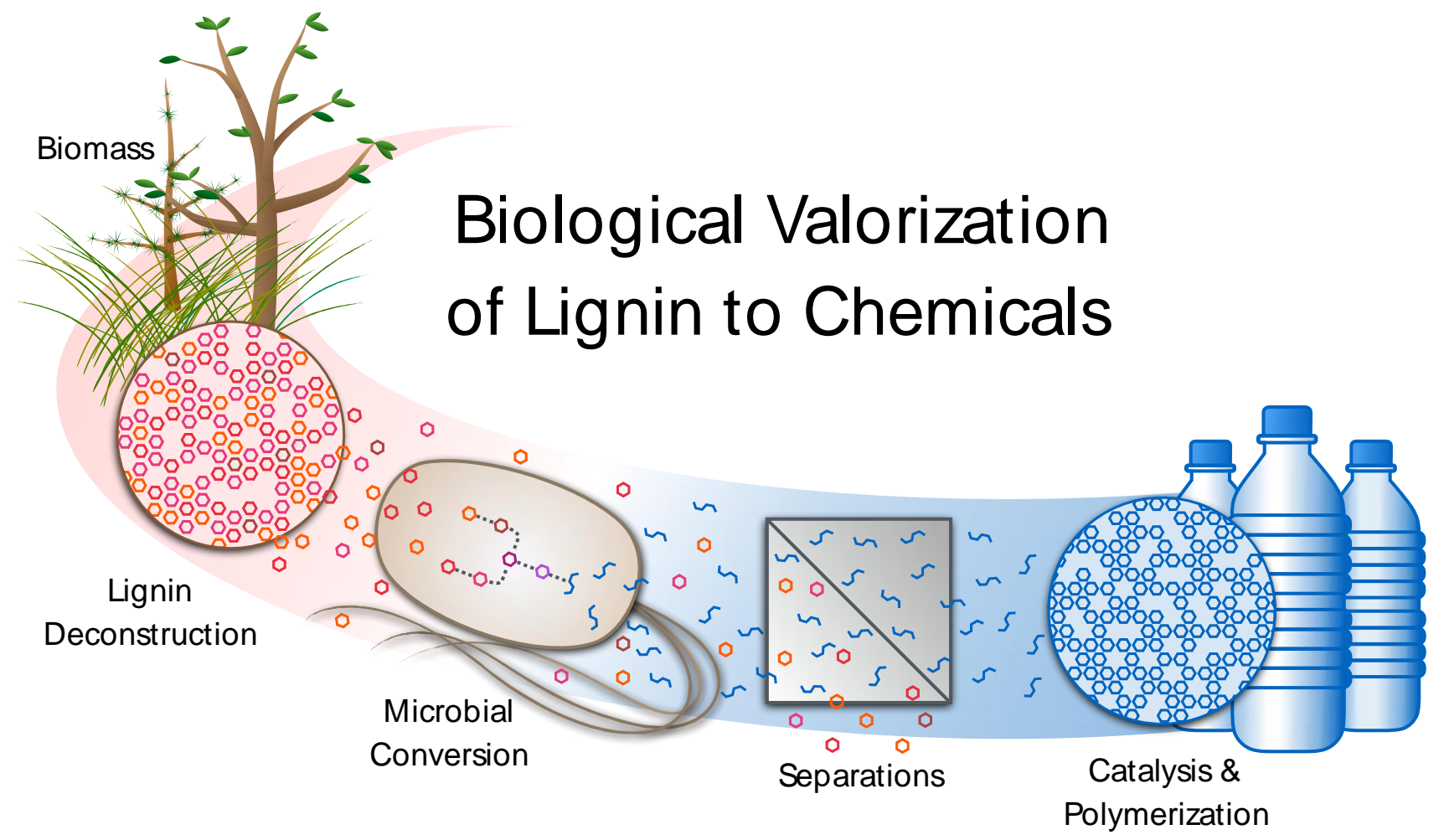

Figure 1. Lignin can be recovered and depolymerized by natural ligninolytic or thermochemical pretreatment. Engineered microbes employ "biological funneling" to convert a heterogeneous mix of aromatic molecules to a single product such as muconate. Following separation, products can be subjected to chemical catalysis to yield a multitude of functional and direct replacements of commodity chemicals.

Lignin as a substrate for microbes: How can we break lignin down in a biorefinery context? The composition of depolymerized lignin varies quite significantly based on the source of the feedstock as well as how that feedstock is processed. Typical biochemical conversion processes employ a mild thermochemical pretreatment step coupled to enzymatic hydrolysis to convert the polysaccharides in biomass to soluble sugars or sugarderived species [14]. For upgrading, lignin-enriched streams will likely be available either from pretreatment (upstream) as a solubilized, fractionated stream or as a solid stream after polysaccharide hydrolysis (downstream). It is worth to point out that complete lignin fractionation from whole biomass is challenging without adversely affecting carbohydrate yields. Here we discuss options for both upstream and downstream lignin isolation and utilization.

Currently, there is a diverse portfolio of options for biomass pretreatment available, some of which are able to partially fractionate lignin and some that are not. Thus far, hydrothermal, dilute-acid, and ammonia-based processes are being deployed at the industrial scale and multiple other methods are being scaled up now in pilot and demonstration facilities. Many elegant bench-scale approaches are being pursued, such as ionic liquids or other solvent-based fractionations that are able to fractionate lignin from whole biomass quite selectively $[15,16]$. Another emerging approach, Reductive Catalytic 
Fractionation (RCF), combines a redox-active catalyst in reducing environments with whole biomass to selectively cleave $\beta-0-4$ linkages [17-20]. RCF processes have captured significant attention as they lead to a narrow chemical slate of monomers and dimers at high yields ( $50 \%)$ on hardwoods such as birch. RCF remains to be broadly deployed in a feedstock-agnostic manner, performing most effectively on hardwoods where the syringyl/guaiacyl (S/G) ratio is high, leading to an enrichment in $\beta-0-4$ linkages. A very recent, exciting report from Luo et al. successfully demonstrated the RCF concept on miscanthus with a yield of nearly $70 \%$ aromatic products from lignin [21]. Lastly, high pH pretreatment approaches, such as the use of $\mathrm{NaOH}$, are able to partially fractionate lignin from biomass, leading to lignin-enriched streams [22-24], but which exhibit a very broad molecular weight distribution from the monomer range to oligomers up to $\mathrm{O}\left(10^{3}\right)$ Da [25]. Clearly, multiple technologies are being actively developed for a "lignin-first" biorefinery approach, and detailed characterization of these streams will be required using a battery of analytical approaches to ascertain their ability to provide lignin streams ideal for biological conversion.

Converse to solubilized lignin obtained during pretreatment or fractionation, residual lignin isolated after polysaccharide hydrolysis will typically be a solid, lignin-enriched substrate contaminated with biological and/or chemical catalysts, depending on the upstream processing. To be amenable for biological utilization, the solid stream will need to be depolymerized, either chemically or biologically. Many catalytic approaches for depolymerizing residual or technical lignins have been reported over the last century, and these studies are outside the scope of this review; the reader is encouraged to see recent reviews from others $[9,26]$. It is noteworthy that high severity hydrolysis or deconstruction approaches aimed at polysaccharides will often chemically modify lignin, often cleaving labile $\mathrm{C}-\mathrm{O}$ linkages and reforming more recalcitrant C-C linkages. Few, if any, studies to our knowledge have been conducted to date on characterization of residual lignin-enriched solids from biomass processing with an ultimate aim to produce chemicals biologically, so this remains an area rich for research and development.

Ideally, lignin streams for microbial conversion would be water-soluble monomers that are able to be metabolized, and obtainable at high concentration, similar to the 100$200 \mathrm{~g} / \mathrm{L}$ sugar streams that one can obtain using common polysaccharide deconstruction strategies. However, nearterm pretreatment and depolymerization approaches are seldom able to produce this type of stream, instead producing highly chemically and physically heterogeneous mixtures that are often in an organic oil phase. Oxidative approaches, whether biological or catalytic, potentially offer a means to produce a slate of water-soluble, low molecular weight species from lignin. However most oxidative depolymerization of lignin conducted to date has been focused on production of valuable aldehydes such as vanillin or ring-opened dicarboxylic acid mixtures [27]. Clearly, significant work needs to be done at the interface between lignin depolymerization and conditioning and biological lignin upgrading approaches to produce streams that are ideal for biological conversion to value-added chemicals, rather than the byproducts of processes aimed solely at sugar upgrading. From our perspective, this represents one of the primary challenges in realizing this technology path for industrial-scale use.

Host Selection. Multiple microbes are able to utilize heterogeneous slates of aromatic compounds as carbon and energy sources. To date, four biological mechanisms have been elucidated to catabolize aromatic compounds [11]. The most well characterized mechanism is via upper pathways to central intermediates such protocatechuate and catechol, which are then cleaved via ring-opening dioxygenases and metabolized further to enter the TCA cycle. Here, we focus in particular on utilization of the classic aromatic catabolic pathways via ring-opening dioxygenases.

The ideal microbe for biological lignin valorization will exhibit the necessary aromatic substrate specificities for the stream of interest, be genetically tractable, stresstolerant, and be able to be domesticated for use in industrial bioreactors. Many candidates exist, and undoubtedly there is not one single best choice present for all lignin streams, but rather the microbe should be paired with and tailored to both the lignin-enriched stream being supplied as substrate as well as with the product being targeted.

Several microbes have been shown to date to be promising for biological lignin valorization including Pseudomonads such as Pseudomonas putida KT2440 [25,28-30] and P. fluorescens [30], Rhodococci including Rhodococcus jostii RHA1 [30,31] and Rhodococcus opacus [32], as well as Acinetobacter baylyi ADP1 [33], Amycolatopsis sp. 75iv2 [30], and the well studied Sphingomonas sp. strain SYK-6 [34-36]. Additionally, some oleaginous yeast exhibit aromatic catabolic pathways, and may be excellent hosts. Several of these microbes naturally accumulate carbon-storage products such as triacylglycerides (TAGs) [31,32] or polyhydroxyalkanoates (PHAs) [25] in addition to having broad aromatic catabolic capabilities, making the wild type strains attractive starting hosts. Other organisms, such basidiomycete fungi and in particular white-rot fungi, have been shown to be the primary organisms responsible for lignin catabolism in most natural environments, depolymerizing and mineralizing lignin at very high yields, up to $80 \%$ [37]. However, genetic tools for these organisms are still undeveloped which, to date, hinders their use as platform 
host. A review from Camarero et al. summarizes the potential of fungi and their ligninolytic enzymes (native and engineered) in lignin-related biotechnologies [38].

To date, we have found that $P$. putida KT2440 offers significant potential as a host for upgrading aromatic compounds to targeted molecules and a huge body of literature has been amassed on its physiology, metabolism, and potential for domestication over the last several decades [39]. Interestingly, de Lorenzo and coworkers recently engineered genome-reduced strains of P. putida KT2440 (EM42 and EM383) including 300 genes that were deemed not necessary for domestication [40]. These strains exhibit enhanced properties over wild type $P$. putida KT2440 in every property reported, including reduced lag times, increased biomass yield, higher growth rates, improved heterologous protein expression, higher tolerance to oxidative stress, and improved cell survival in stationary phase $[40,41]$. These strains were reduced in flagellar machinery, which is not necessary for stirred bioreactor cultivation, four prophages, three components of DNA restriction-modification systems, and two transposons. Lieder et al. used the same domesticated strains to show that heterologous protein expression was enhanced by $40 \%$ in the engineered strain (using green fluorescent protein as a model) [41]. Further domestication of $P$. putida will likely continue to make it an attractive chassis for metabolic engineering applications in biological lignin valorization.

Three additional paradigms have more recently emerged that employ aerobic or anaerobic mechanisms, as recently reviewed by Fuchs et al. [11]. To date, several species have been described to accomplish aromatic catabolism via anaerobic mechanisms, including Azoarcus sp. ClB [42], Thauera aromatica [43], Aromatoleum aromaticum [44], Rhodopseudomonas palustris [11], and others [4547]. Certainly aromatic catabolism via anaerobic paradigms may ultimately be of interest for biotechnological purposes, given the simpler, often cheaper processing conditions required. More efforts here would be interesting to compare aerobic and anaerobic aromatic catabolic microbes to understand differences in substrate specificity, catabolic rates, and potential target products.

Enzyme-Microbe Synergy. Quite commonly in lignin depolymerization, it is challenging to produce solely monomeric aromatic species. For example, alkaline extraction of lignin from biomass, which is a simple process to obtain a stream of lignin-enriched material, often results in a soluble fraction of lignin that ranges from monomers to oligomers with molecular masses well over $10^{3} \mathrm{Da}$ [23-25]. Emerging processes, such RCF, also produce dimeric and oligomeric compounds that exhibit C-C linkages, which are difficult to break at mild conditions in reductive or hydrolytic (non-oxidative) environments. In light of high molecular weight species being present in lignin-enriched streams, the concept of bacterial ligninolytic activities has emerged only in the last few years and enables extracellular turnover of lignin oligomers to low molecular weight compounds. Both new and traditional ligninolytic enzyme activities have been discovered and characterized in microbes such as $R$. jostii RHA1 [48-51], Bacillus subtilis, Amycolatopsis sp., and $P$. putida MET94 [52-54]. Additionally, new, more specific enzymes that target specific bonds in lignin, for example $\beta$-O-4 linkages, are emerging [55]. Further enzyme discovery and characterization will be necessary going forward to understand the full suite of bacterial ligninolytic enzymes available. High-throughput screens like that developed by Strachan et al. will enable rapid detection of additional activities from environmental samples relevant to lignin degradation $[56,57]$.

Towards understanding how microbes break down high molecular weight lignin in an extracellular fashion, Salvachúa et al. recently demonstrated that multiple aromatic catabolic microbes actively secrete ligninolytic enzymes, namely laccases and peroxidases, which leads to a significant extent of depolymerization of soluble, high molecular weight lignin [30], as illustrated in Figure 2. The resulting lower molecular weight compounds were taken up and converted to carbon storage products such as TAGs or PHAs, depending on the microbe. The ability of a microbe to secrete ligninolytic enzymes and uptake the resulting low molecular weight aromatics is akin to the Consolidated Bioprocessing (CBP) concept applied to polysaccharide conversion to ethanol [58,59]. Subsequently, Yuan et al. demonstrated the addition of exogenous, commercial laccase from Trametes versicolor to $R$. opacus growth on commercial Kraft lignin, demonstrating a significant increase in TAG yield from 8 $\mathrm{mg} / \mathrm{L}$ to $145 \mathrm{mg} / \mathrm{L}$ [60].

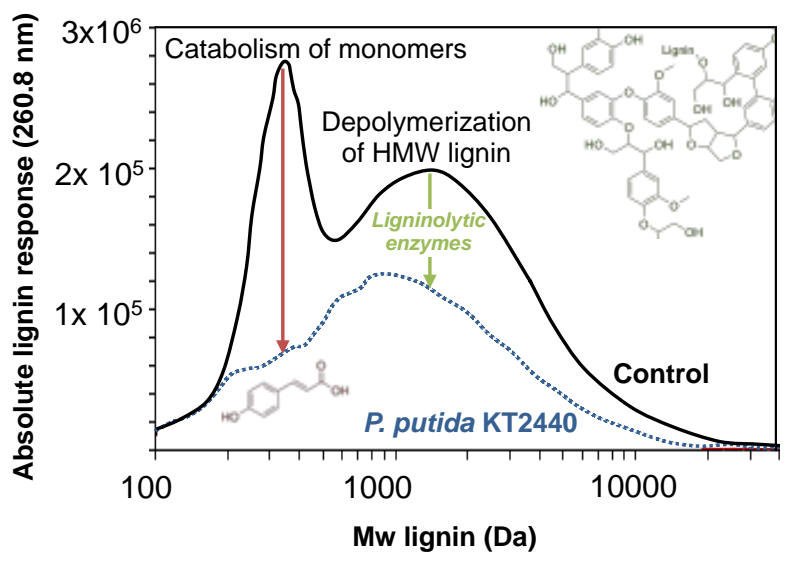

Figure 2: Gel-permeation chromatogram demonstrating that $P$. putida KT2440 is able to both catabolize low molecular weight aromatic compounds and simultaneously depolymerize high molecular weight (HMW) lignin oligomers. Data adapted from Salvachúa et al. [30]. 
These initial demonstrations of microbes working in concert with ligninolytic enzymes, either endogenous [30] or using exogenous commercial sources [60], presents exciting opportunities to more deeply understand how microbes and ligninolytic enzymes work in concert and to harness this potential for biological lignin valorization. Although many studies have aimed to understand individual ligninolytic enzymes or aromatic catabolism by individual microbes, many questions arise at the interface in terms of how ligninolytic enzymes are secreted, how they act on real lignin substrates, what low molecular weight aromatics are produced, and how those aromatic compounds are taken up and catabolized by the microbe. Indeed, understanding the relative rates of these likely separate processes will be critical for engineering optimal biological solutions if ligninolytic enzymes are a necessary component of a biological system for depolymerizing high molecular weight lignin oligomers in the extracellular milieu. Similar to work done on CBP approaches applied to polysaccharides, one can readily envision overexpressing endogenous ligninolytic enzymes or introducing new enzymatic activities for secretion. However, it is currently unclear how much ligninolytic enzymes will be needed and what the optimal mixtures of these enzymes will be, which will likely highly depend on the lignin stream in question. This challenge somewhat mirrors those faced in cellulase cocktail development, wherein complex mixtures of complementary enzymes are required for cellulose and hemicellulose depolymerization [61]. However, with lignin, the enzyme activities are much less understood, in many cases are not highly specific producing simultaneous depolymerization and repolymerization of aromatic compounds [62] and the substrate generally is much more complex than polysaccharides. Combining powerful biological -omics tools and advanced chemical analytics to understand how natural systems utilize these complex substrates offers an obvious starting point for understanding and designing enzyme-microbe interactions to optimally depolymerize lignin and catabolize the resulting monomeric species to targed compounds.

Expanding Substrate Specificity. Another key aspect of biological funneling involves a chosen microbe being able to conduct efficient transport and catabolism of a broad range of aromatic compounds simultaneously. While undissociated aromatic acids are capable of passively diffusing across bacterial cell membranes, active transporters have been described and are likely to be important in natural environments where these molecules are present in low concentrations [63-65]. Additionally, Michalska et al. demonstrated that some bacterial ATPbinding cassette $(A B C)$ transporters are able to transport a significant number of benzoate derivatives including vanillic acid and 4-hydroxybenzoic acid [66]. From this library, the authors were able to solve seven crystal structures of solute-binding proteins (SBPs) from $A B C$ transporters with four aromatic ligands. Beyond monomeric aromatic compounds, it is not currently established if higher molecular weight species (e.g., dimers) are able to cross cell membranes for intracellular cleavage.

Many metabolic pathways for single aromatic compounds have been mapped to date in microbes such as $R$. jostii RHA1, Sphingobium sp. Strain SYK-6 [34], P. putida KT2440, and other model aromatic-catabolic microbes, especially for hydroxycinnamic acids (which can be readily derived from herbaceous feedstocks) or aromatics relevant to bioremediation and high severity lignin depolymerization $[67,68]$, as illustrated in Figure 3 . The conversion of phenol to catechol by several different phenol hydroxylases have been described [69-71], but catabolic pathways for several other key lignin-derived substrates have not been fully elucidated yet, limiting the ability to conduct metabolic engineering to expand substrate specificities to some common lignin-derived compounds. Guaiacol (2-methoxyphenol), for example, is demethylated to catechol via a cytochrome P450 enzyme [72-74], but the enzyme has not been well characterized to date (Figure 3). As all lignin, and especially that from softwoods, contain substantial amounts of G-type lignin, guaiacol utilization represents an important target. Additionally, the specific pathway for the biological utilization of syringol (2,6-dimethoxyphenol) remains unknown, although this could be a ubiquitous, if poor, natural mediator for some laccases [75]. Generally, expanding the substrate specificities of aromatic catabolic microbes will require the discovery of microbes able to utilize these compounds as sole carbon sources and the subsequent discovery of new enzymatic activities therein.

Metabolic Engineering and Synthetic Biology in Biological Lignin Valorization. The biological upgrading of lignin-derived aromatic compounds provides the potential to produce several classes of molecules including those that maintain the aromatic ring [76], ring-opened species native to the aromatic catabolic pathways, and products derived after the carbon enters central metabolism. Outside of the obvious need to produce a certain type of fuel or chemical, optimal target selection will need to be tailored to the lignin stream for upgrading, the host, and the ease of separation and purification.

In terms of aromatic compound production, natural intermediates in the upper pathways of lignin catabolism could be produced by eliminating enzymes responsible for their further metabolism [76]. In addition, routes to direct biological conversion of aromatic molecules known to be lignin monomers to other aromatic products, as recently reviewed by Thompson et al. [77], have been described but are not numerous, presenting an interesting opportunity for gene discovery and synthetic biology. Unless the lignin-derived stream is already quite homogeneous, however, it will likely be difficult to 
produce a single aromatic compound, other than targeted central intermediates such as catechol or protocatechuate, in high yields.

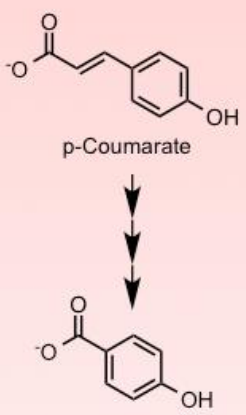

4-Hydroxybenzoate PobA
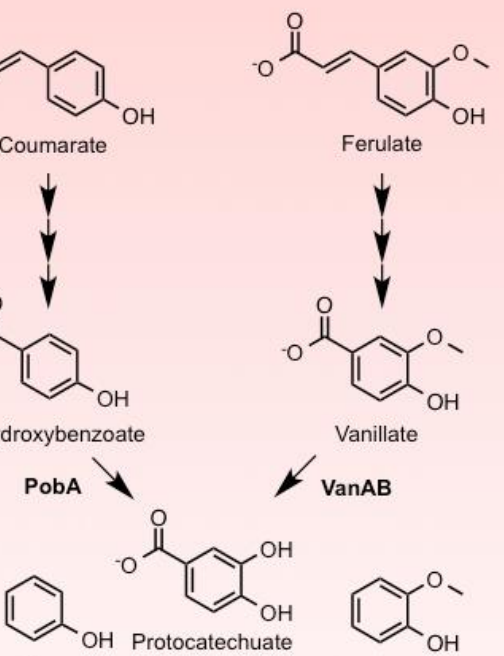

Phenol PheA

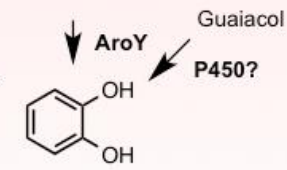

Catechol

$\downarrow$ CatA

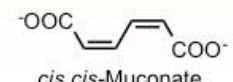

cis, cis-Muconate somerization

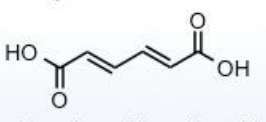

trans, trans-Muconic acid

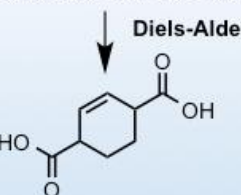

2-Cylcohexene-1,4-dicarboxylic acid

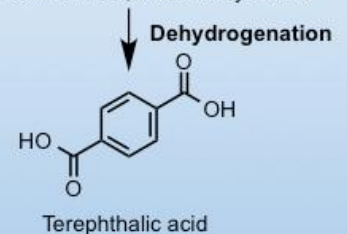

Figure 3. Microbes capable of metabolizing aromatic monomers derived from depolymerized lignin, such as $p$ coumarate, ferulate, 4-hydroxybenzoate, vanillate, phenol, or guaiacol, convert these molecules through "upper pathways" to two central intermediates, protocatechuate and catechol. Protocatechuate can be decarboxylated by AroY to form catechol, which is then subjected to ring-opening to form cis-cis-muconate by CatA, a catechol 1,2-dioxygenase. Subsequently, muconic acid can be chemo-catalytically converted to (a) adipic acid via hydrogenation, or (b) terephthalic acid via isomerization, Diels-Alder reaction with ethylene, and dehydrogenation.

Oxidative aromatic ring cleavage is conducted via intra- or extra-diol ring enzymes $[78,79]$, the type of which differs between hosts. For catechol, ring cleavage can be conducted by two enzymes, a 1,2-catechol dioxygenase or a 2,3-catechol dioxygenase. For protocatechuate, this reaction can be conducted via three enzymes, with specificity in the 2,3 (meta), 4,5 (meta), and 3,4 (ortho) positions. Interestingly, these enzymes give rise to distinct ring-cleavage products that are then metabolized through mostly non-overlapping pathways to funnel the aromaticderived carbon to the tricarboxylic acid cycle. These pathways lead to both different carbon yields entering central metabolism and different reducing equivalent generation [29], which can be tuned towards product yields and redox balance. Directed evolution as well as rational protein engineering based on recent investigations into the structure-activity relationships of these enzymes have lead to the development of ringcleavage dioxygenases with increased activity and altered substrate specificity [80-86].

Multiple products have been produced to date from ringopening reactions from lignin in engineered hosts. The most obvious intermediate to produce is cis,cis-muconate, the ortho-cleavage product of catechol. Cis,cis-muconate can in turn be readily separated and catalytically hydrogenated to adipic acid (Figure 3). Much of the initial work for producing muconate has focused on using sugars as a substrate wherein aromatic amino acid biosynthesis is linked to protocatechuate, which can be converted to catechol via expression of a protocatechuate decarboxylase [87,88]. Recently, Vardon et al. demonstrated that cis,cis-muconate can be produced in an engineered strain of $P$. putida KT2440 from ligninderived aromatics such as $p$-coumarate and ferulate as well as the common model aromatic compound, benzoate [28]. Several metabolic bottlenecks exist in this particular strain and more generally in pathways to produce cis,cismuconate. In particular, the accumulation of protocatechuate, resulting from insufficient activity of the decarboxylase that converts this molecule to catechol, has been observed in and is central to strategies to produce cis,cis-muconate from both sugars and lignin-derived aromatics molecules [28,89-91]. Sonoki et al. recently published a study that will likely help overcome this protocatechuate decarboxylase bottleneck [90]. Namely, they demonstrated that co-expression of additional genes that are naturally co-expressed with homologous decarboxylases leads to enhanced conversion to cis,cismuconate from vanillin [90]. The functions of these additional proteins have not been entirely elucidated, and represent a target for further engineering. Beyond the 
protocatechuate decarboxylase, Vardon et al. revealed substantial accumulations of 4-hydroxybenzoate (4-HB), when muconate was produced from $p$-coumarate, and vanillate, when the substrate was ferulate, indicating insufficient activity of the 4-HB hydroxylase (PobA) and vanillate demethylase (VanAB), respectively. Interestingly, Sonoki et al. also observed an accumulation of vanillate when producing muconate from vanillin, another intermediate in the ferulate pathway, in an Escherichia coli-based production strain. The manifestation of this bottleneck in an unrelated, heterologous host lacking endogenous regulation suggests that muconate might act on the vanillate demethylase directly. This hyposthesis was further supported by the authors' finding that vanillate did not accumulate in their $E$. coli system when catechol was the end product. Further investigation will be needed to elucidate and overcome such bottlenecks in order to enable the efficient production of cis,cismuconate from lignin-derived aromatic molecules.

Beyond cis,cis-muconate, other products have been produced that fall in the lower pathways between the central aromatic intermediates and central carbon metabolism, including 2-pyrone-4,6-dicarboxylic acid (PDC) [92,93], pyridine 2,4-dicarboxylic acid, pyridine 2,5dicarboxylic acid [94], muconolactone [95], $\beta$-ketoadipate [95], 2-hydroxymuconic semialdehyde [96], and 3carboxymuconate [97]. These targets represent novel intermediates not readily obtained from sugars, except through the shikimate pathway via amino acid biosynthesis [87]. PDC in particular has been studied in great detail by Shigehara et al. in terms of its polymer properties. Certainly other intermediates exist in these pathways with significant chemical functionality, representing novel building blocks that can be derived from lignin-derived aromatic compounds with high atom efficiency.

Products from central carbon metabolism include those naturally produced by a given strain, such as PHAs or TAGs, both of which have been demonstrated on ligninderived streams $[25,30,32,60]$. Additionally, one could envision producing virtually any target molecule derived from central metabolism, including fatty-acid pathway derived products, isoprenoid pathway-derived products, alcohols, short-chain acids, or myriad other species of interest [98]. This enables leveraging the massive body of work conducted to date in metabolic engineering from sugar, glycerol, or other conventional substrates. Johnson et al. demonstrated the production of pyruvate and Llactate as examples of such products [29]. Importantly, this work also demonstrated that the lower pathways of catechol and protocatechuate metabolism are interchangeable and that, because they differ in carbon yield, cofactor regeneration, and the form in which they ultimately enter the TCA cycle (i.e. combinations of acetylCoA, pyruvate, and/or succinate), the pathway employed can have a profound effect on product yield. Given the rapid expansion of this field, it is likely that many more products will be targeted in the near future.

Biological Lignin Valorization and Process Integration. Microbial upgrading of lignin to a specific chemical will require a significant amount of a priori consideration of process feasibility and integration. As described above, lignin streams for microbial conversion would ideally consist of a liquor with high monomeric species content. However, to date, monomeric species in lignin streams are still in the range of few $\mathrm{g} / \mathrm{L}$ units $[25,30]$. This significantly limits the achievable titers of target molecules from aromatic compounds via biological funneling. Thus, enhanced lignin solubilization strategies or concentration methods are key for further process integration. Once an ideal lignin liquor production process has been achieved, the toxicity of the different aromatic molecules in the liquor must also be considered. For instance, it has been reported that benzoate concentrations higher than $50 \mathrm{mM}(\sim 7 \mathrm{~g} / \mathrm{L})$ is toxic to $P$. putida KT2440 [99]. Consequently, different fermentation strategies must be developed to feed the bioreactors at the highest catabolic rate, without reaching toxicity limits. Moreover, it has been suggested that high glucose concentrations can provoke catabolic repression, which hinders aromatic consumption [100]; however, glucose in lignin streams can be quite variable so every case must be evaluated separately considering the detailed liquor composition, bacterial host, and target compound. As an example, some of the feeding strategies used to produce cis,cis-muconate from pure aromatics, such as benzoate or catechol, are based on DO-stat fed batch, pH-stat fedbatch, or fed-batch by pulses $[99,101,102]$ to avoid both toxicity and catabolite repression.

Beyond fermentation, downstream separations of target molecules will play a key role in determining the industrial viability of chemicals produced biologically from lignin. Separation of biologically derived metabolites can be broadly grouped into three product categories: (1) intracellular products, (2) extracellular water-soluble products, and (3) extracellular phase-separating products. Recovery of intracellular metabolites (e.g., TAGs, free fatty acids, carotenoids, PHAs) typically involves removing cells from the aqueous growth media for solvent extraction, or rupturing cell walls in situ via chemical, enzymatic, or mechanical means $[103,104]$. The dilute nature of cell cultures makes dewatering and cell wall rupturing energy intensive, necessitating high culture titers. With regards to lignin utilization, residual ligninderived monomeric and oligomeric species may problematic if they are carried over during product recovery, requiring costly cleanup steps. Recovery of extracellular water-soluble products, such as substrates derived from lignin via oxidative ring-opening pathways (e.g., muconate, catechol, protocatechuate, vanillin) or 
metabolites from the TCA cycle (e.g., short-chain acids, alcohols, polyols), requires overcoming the target molecule's hydrophilicity. Separation strategies must be tailored to the molecule of interest that incorporate technologies such as membranes, chromatography, reactive distillation, crystallization, or solvent extraction [104]. The key challenge is to recover the product selectively in the presence of other water-soluble species, such as non-target metabolites, broth additives, biomass deconstruction impurities, and residual lignin-derived species. Ideally, the target molecule will possess physicochemical properties (e.g., solubility with temperature or $\mathrm{pH}$, boiling point, solvent partitioning coefficient) that greatly differentiate its behavior from non-target species. Lastly, recovery of extracellular phase-separating products, such as long-chain fatty acids, fatty acid derivatives (e.g., fatty alcohols, fatty esters, long-chain hydrocarbons), and isoprenoids derivatives (e.g., isoprene, farnesene, bisabolene), invokes the target molecule's hydrophobicity to avoid extensive downstream unit operations. However, emulsion formation is still a concern when separating hydrophobic liquid products due to interactions with broth salts, polar lipids, proteins, polysaccharides, and colloidal particles [105]. With regards to lignin, residual oligomers may also increase emulsion formation, necessitating effective lignin depolymerization strategies via chemical, mechanical, or biological means. Overall, separation strategies for ligninderived chemicals must account for the energy, operational, and capital costs in an economically and environmentally positive manner to warrant further development and scale-up beyond the bench.

In addition to direct biological processing, hybrid biological and chemo-catalytic approaches to lignin valorization can leverage the ability of microorganisms to reduce substrate heterogeneity and chemo-catalysis to facilitate continuous, high-throughput chemical transformations of target metabolites. For substrates derived biologically from lignin via oxidative ring-opening pathways, direct petrochemical replacements can be targeted via catalysis, such as adipic acid [28,87] and terephthalic acid [106] (Figure 3), as well as novel derivatives that do not have petrochemical analogues. This offers exciting opportunities to utilize the aromaticity and oxygen content of lignin for conducting atom efficient transformations to diversify the chemical products derived from biomass. For biological substrates derived from lignin via the TCA cycle, advances in catalysis for sugar-based feedstocks can be leveraged, ideally accelerating development in both areas [107-109]. As noted above, impurities associated with lignin streams and biological conversion processes will also need to be taken into account due to their potential impact on catalyst activity, selectivity, and stability [110]. However, as technology advances in the areas of both biological and chemo-catalytic processing, unique synergies may be afforded for lignin-derived chemicals.

Transformative Technologies for Lignin Valorization. As the field of biological lignin valorization advances, the development of technologies capable of fractionating lignin from biomass into a process stream ideal for microbial conversion becomes critical. As mentioned above, the objective function of pretreatment approaches for lignocellulosic material are focused on generating sugars for conversion to chemicals and fuels [14,111,112]. Pretreatment approaches in future biorefineries that utilize both lignin and sugars from lignocellulosic feedstocks will need to meet two objective functions of (1) generating high sugar yields in one process stream and (2) yielding high concentrations of low molecular weight lignin degradation products in a separate process stream. Given the inherent heterogeneity of chemical bonds within lignin polymers and substantial differences in the chemical makeup of lignin between feedstocks, the development of a single pretreatment approach to fulfill both of these objectives becomes very challenging. However, genetic modification of the lignin polymer in the starting feedstock as a means to increase the homogeneity of chemically labile inter-unit linkages is poised to make great advances in achieving these goals (Figure 4). Lignin biosynthesis has been studied for decades and, more recently, genetic manipulations of these pathways have been employed in the context of increasing pulping efficiency $[113,114]$ or in the context of a biorefinery to increase saccharification yield $[115,116]$. These feedstocks containing engineered lignins have been shown to meet the objective function of increasing saccharification yields, but they have not been yet extensively studied with the aim of producing lignin degradation products that are readably catabolized by microorganisms. From what we currently know about the metabolic pathways in the microorganisms discussed above, hydroxycinnamates ( $p$-coumarate and ferulate), vanillate, guaiacol, and other aromatic compounds can be readily metabolized. Genetic modifications of lignin to include aromatic compounds that are able to be easily metabolized within the lignin polymer would likely be an attractive means to produce a stream of lignin degradation products rich in key aromatic species that can be biologically valorized. In fact, some of these modification approaches already exist. For example, recent work by Wilkerson et al. [5] incorporated increased amounts of ferulate into the lignin polymer within poplar (Figure 4B). Incorporating more ferulate monomers inherently increases the amount of ester linkages, which are readily cleaved under mild alkaline pretreatment. Presumably, lignin of this nature would yield significantly increased amounts of ferulate into the black liquor stream, which could be an ideal substrate for microbial conversion. We also note that some naturally occurring lignins in certain plant species contain uncommon 
chemical makeups that may produce much more homogenous slates of lignin degradation products better suited for microbial catabolism. One possible example is the recently discovered C-lignin that is composed of caffeyl alcohol in the seed coats of some Vanilla and Cactaceae species [2,117], shown in Figure 4C. With the

\section{A. Wild type lignin}

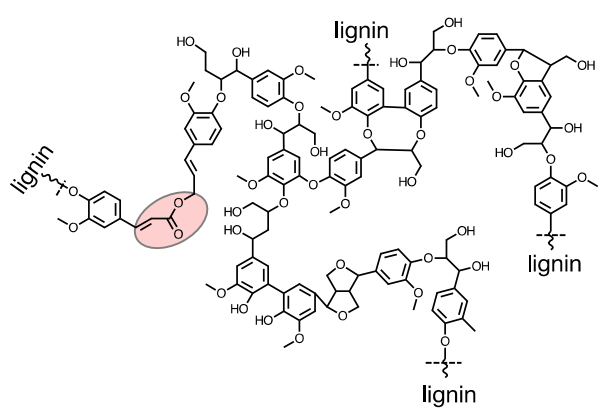

B. Engineered ferulated lignin

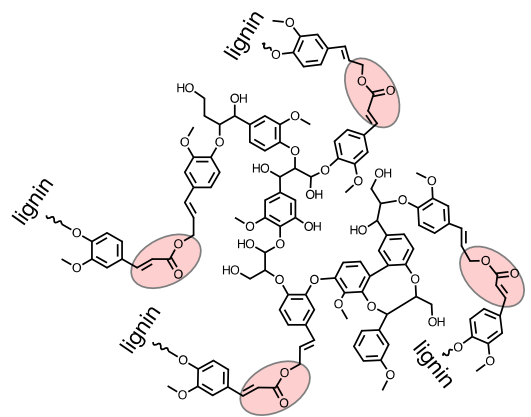

discovery of this atypical C-lignin, more advances in lignin modifications are expected as prospecting for other unique lignins continues. These new lignin discoveries will likely enable more novel lignin modifications that could play a key role in a future biorefinery that utilizes lignin.

Figure 4. (A) Representation of a wild type lignin structure, adapted from [118]. Pink highlights indicate ester linkages that are readily cleaved under alkaline conditions. (B) Representation of engineered ferulated lignin reported by Wilkerson et al. in [5], here too pink highlights are used to denote the increase in ester linkages in this lignin from wild type lignin. (C) A representation of recently discovered C-lignin from the seed coats of some Vanilla and Cactaceae species reported in $[2,117]$. Blue highlights indicate labile ether linkages.

Major advancements are also needed in analytical technologies to quantify and track the conversion of lignin degradation products within real lignin-enriched process streams. These tools are crucial in assessing the overall effectiveness microbes have on the conversion of lignin, for ensuring process reproducibility, and for understanding the metabolic behavior each microorganism exhibits in a chemically complex matrix. Most analytical techniques for lignin are aimed at elucidating the native structure of the lignin polymer through controlled chemical deconstruction (e.g. derivitization followed by reductive cleavage) [119]. However, process streams rich in lignin degradation products need to be preserved throughout analysis in order to assess the changes occurring during biological conversion. These streams are inherently complex containing a variety of low and high molecular weight lignin degradation products with a wide range of chemical functionalities, sugar degradations products, extractives, and will also likely contain particulates. As a result, these solutions tend to be relatively metastable where changes to $\mathrm{pH}$ or the addition of solvents during analytical workup causes further reactions and maintaining sample integrity throughout an analytical procedure becomes quite challenging. One commonality between various lignin rich process streams (e.g. black liquors, pyrolysis oils, pyrolytic lignins, etc.) is their stability in high $\mathrm{pH}$ aqueous environments. To that end, older techniques that have found somewhat niche applications in the pulp and paper industry for identifying low molecular weight compounds in high pH kraft black liquors could be adapted to monitor lignin based fermentations. For example, a derivatization method originally reported in 1986 by Niemelä and Sjöström [120] for use in identifying low molecular weight aromates and aliphatic acids in kraft black liquors has been recently adapted to quantify and track the catabolism of aromates and the production of muconic acid during the growth of engineered $P$. putida KT2440CJ103 in alkaline pretreatment liquor (APL) from corn stover [28]. Additionally, this method achieved good results in tracking a large slate of chemical species during the growth of a variety of microorganisms in corn stover derived APL and yielded much information on the metabolic differences between species [30]. Capillary electrophoresis is another promising technique that has found use in the pulp and paper industry for online monitoring of kraft black liquor composition [121,122] and could likely be adapted for online monitoring occurring in lignin-enriched solutions. Cutting edge electrophoretic techniques such as Gradient Elution Moving Boundary Electrophoresis (GEMBE) also hold much promise for monitoring biological lignin conversion processes [123]. GEMBE appears to be remarkably adapted for online monitoring of these lignin conversion processes because it is comprised of low cost components, can handle particulates in the feed, and can be set up in multidimensional modes to achieve excellent resolution of compounds in complex matrices [124]. These techniques will likely find widespread use in monitoring biological conversion of lignin as the field progresses.

Conclusions. Biological strategies for lignin valorization hold significant promise for overcoming the heterogeneity of lignin, which is the primary challenge in upgrading this 
complex substrate to value-added chemicals. Effectively harnessing the intrinsic capabilities of biology to valorize lignin will require a substantial research and development effort going forward in understanding how to co-design lignin solubilization strategies for biological conversion and design microbial biocatalysts optimized for both the feed stream and targeted product. Certainly significant research and development opportunities and challenges remain to ascertain the viability of this new approach.

\section{Acknowledgements}

We acknowledge funding from the US Department of Energy Biotechnologies Office. GTB and DRV also acknowledge funding from the Direct Catalytic Conversion of Biomass to Biofuels (C3Bio), an Energy Frontier Research Center funded by the U.S. Department of Energy, Office of Science, Office of Basic Energy Sciences, Award Number DE-SC0000997. GTB also acknowledges funding from the BioEnergy Science Center, a U.S. Department of Energy Bioenergy Research Center supported by the Office of Biological and Environmental Research in the DOE Office of Science. We thank our many colleagues and collaborators for helpful discussions around the topic of microbial lignin valorization.

\section{Annotations for References:}

Of outstanding interest

** $[3,5,18-20,28,30,40,56,94,95,119]$

Of special interest

* $[25,38,55,60,90]$

Bonawitz ND, Kim JI, Tobimatsu Y, Ciesielski PN, Anderson NA, Ximenes E, Maeda J, Ralph J, Donohoe BS, Ladisch M, Chapple C: Disruption of Mediator rescues the stunted growth of a lignin-deficient Arabidopsis mutant. Nature 2014, 509:376-380.

** The authors describe genetic modifications of lignin biosynthesis pathways in Arabidopsis that highlight the dispensability of $\mathrm{S}$ and $\mathrm{G}$ units. Here the authors produce a mutant Arabidopsis (med5a/5b ref8-1) that contains lignin consisting almost entirely of $\mathrm{H}$ units without significantly stunting the plant growth compared to the wild type.

Wilkerson C, Mansfield S, Lu F, Withers S, Park J-Y, Karlen $\mathrm{S}$, Gonzales-Vigil E, Padmakshan D, Unda F, Rencoret J: Monolignol ferulate transferase introduces chemically labile linkages into the lignin backbone. Science 2014, 344:90-93.

** This work details an approach for genetic modification of the lignin polymer in poplar wherein increased amounts of ferulate were incorporated into the lignin structure. The addition of ferulate increases the amount of ester linkages which are more readily cleaved during alkaline pretreatment, thus increasing saccharification yields.

Ferrini P, Rinaldi R: Catalytic Biorefining of Plant Biomass to Non - Pyrolytic Lignin Bio - Oil and Carbohydrates through Hydrogen Transfer Reactions. Angewandte Chemie International Edition 2014, 53:8634-8639.

** The authors demonstrate a lignin depolymerization scheme using a Raney Ni catalyst in isopropanol with $\mathrm{H}_{2}$ to produce a large range of lignin-derived aromatics via solvolysis and catalytic hydrogen transfer reactions.

Van den Bosch S, Schutyser W, Vanholme R, Driessen T, Koelewijn S-F, Renders T, De Meester B, Huijgen W, Dehaen $W$, Courtin $C$ : Reductive lignocellulose fractionation into soluble lignin-derived phenolic monomers and dimers and processable carbohydrate pulps. Energy \& Environmental Science 2015.

** This study reports a demonstration of the reductive lignocellulose fractionation approach wherein birch lignin is depolymerized at a yield exceeding $50 \%$ to a small slate of monomeric methoxyphenols and $20 \%$ of phenolic dimers using $\mathrm{Ru} / \mathrm{C}$ in methanol with $\mathrm{H}_{2}$. The authors examine a broad slate of conditions and demonstrate catalyst recyclability.

Parsell T, Yohe S, Degenstein J, Jarrell T, Klein I, Gencer E, Hewetson B, Hurt M, Im Kim J, Choudhari H: A synergistic biorefinery based on catalytic conversion of lignin prior to cellulose starting from lignocellulosic biomass. Green Chemistry 2015, 17:1492-1499.

** Parsell and co-workers used a bimetallic catalyst with reduced $\mathrm{Pd}$ and ionic zinc on carbon with methanol and $\mathrm{H}_{2}$ to depolymerize lignin in intact hardwood biomass. The authors demonstrate a yield of two methoxyphenols from lignin up to $54 \%$ yield.

Linger JG, Vardon DR, Guarnieri MG, Karp EM, Hunsinger GB, Franden MA, Johnson CW, Chupka G, Strathmann TJ, Pienkos $\mathrm{PT}$, et al.: Lignin valorization through integrated biological funneling and chemical catalysis. Proc. Natl. Acad. Sci. 2014, 111:12013-12018.

* This study represents the first demonstration of the biological funneling concept described in this review. Linger and co-workers demonstrated conversion of a lignin-enriched, biomass-derived stream to mediumchain-length polyhydroxyalkanoates (PHAs) in Pseudomonas putida KT2440 and conversion of the resulting PHAs to both hydroxy acids and hydrocarbons.

** Vardon DR, Franden MA, Johnson CW, Karp EM, Guarnieri MT, Linger JG, Salm MJ, Strathmann TJ, 
Beckham GT: Adipic acid production from lignin. Energy \& Environmental Science 2015, 8:617-628.

This paper was the first demonstration of muconic acid production in an engineered Pseudomonas putida KT2440 strain from lignin. The resulting muconate was recovered and catalytically upgraded to adipic acid.

Salvachúa D, Karp EM, Nimlos CT, Vardon DR, Beckham GT: Towards lignin consolidated bioprocessing: simultaneous lignin depolymerization and product generation by bacteria. Green Chemistry 2015, 17:49514967.

** This comprehensive study examines lignin conversion, depolymerization, aromatic catabolism, and product accumulations on a process-relevant stream with 14 bacteria. The study demonstrates that Amycolatopsis sp., two Pseudomonas putida strains, Acinetobacter baylyi ADP1, and Rhodococcus jostii RHA1 are able to convert a significant amount of solubilized lignin including highmolecular weight species via production of ligninolytic enzymes.

Camarero S, Martínez MJ, Martínez AT: Understanding lignin biodegradation for the improved utilization of plant biomass in modern biorefineries. Biofuels, Bioproducts and Biorefining 2014, 8:615-625.

* This review presents some of achievements in the field of lignin biodegradation by fungi and ligninolytic enzymes giving insight of the applicability of these enzymes in biotechnological processes.

Martínez-García E, Nikel PI, Aparicio T, de Lorenzo V: Pseudomonas 2.0: genetic upgrading of $P$. putida KT2440 as an enhanced host for heterologous gene expression. Microb Cell Fact 2014, 13:159.

** In the interest of developing a host well-suited for life as a microbial cell factory, Martínez-García deleted 4.3\% of the entire genome of Pseudomonas putida KT2440 including 300 genes that they deemed superfluous or deleterious to its performace in this role. The broad benefits they demonstrate using their genome-reduced chassis should compel others to consider whether their own hosts might not benefit from similar streamlining.

Picart $P$, de María PD, Schallmey A: From gene to biorefinery: microbial $\beta$-etherases as promising biocatalysts for lignin valorization. Frontiers in Microbiology 2015, 6.

* This publication reviews emerging types of enzymes involved in lignin deconstruction, namely glutathionedependent $\beta$-etherases. These enzymes selectively cleave $\beta-0-4$ aryl-ether bonds, the most abundant bond found in lignin.

Strachan CR, Singh R, VanInsberghe D, levdokymenko K, Budwill K, Mohn WW, Eltis LD, Hallam SJ: Metagenomic scaffolds enable combinatorial lignin transformation. Proceedings of the National Academy of Sciences 2014, 111:10143-10148. Emerging

** This study introduces cellular and community-wide networks action on aromatic polymers as well as novel toolkits to engineer multiple organisms, exploiting ecological design principles, for further lignin transformation. These types of sophisticated tools will be essential for discovery new ligninolytic enzymes and aromatic catabolic pathways.

Zhao C, Xie S, Pu Y, Zhang R, Huang F, Ragauskas AJ, Yuan JS: Synergistic enzymatic and microbial lignin conversion. Green Chemistry 2015

* This study demonstrates that the combination of a commercial laccase and an oleaginous bacterium can lead to higher lipid yields on Kraft lignin.

Sonoki T, Morooka M, Sakamoto K, Otsuka Y, Nakamura $M$, Jellison J, Goodell B: Enhancement of protocatechuate decarboxylase activity for the effective production of muconate from lignin-related aromatic compounds. Journal of biotechnology 2014, 192:71-77.

* This study demonstrates one means of enhancing activity of the protocatechuate decaboxylase that is central in converting lignin-derived aromatic molecules to products such as muconic acid. The mechanism of this protocatechuate decarboxylase activity enhancement is an interesting open question.

Mycroft Z, Gomis M, Mines P, Law P, Bugg TD: Biocatalytic conversion of lignin to aromatic dicarboxylic acids in Rhodococcus jostii RHA1 by re-routing aromatic degradation pathways. Green Chemistry 2015, 17:49744979.

** This study demonstrates production of 2 novel carboxylic acids derived from lignin in an engineered strain of Rhodococcus jostii RHA1.

Okamura-Abe Y, Abe T, Nishimura K, Kawata Y, Sato-Izawa K, Otsuka Y, Nakamura M, Kajita S, Masai E, Sonoki T: Beta-ketoadipic acid and muconolactone production from a lignin-related aromatic compound through the protocatechuate 3, 4-metabolic pathway. Journal of Bioscience and Bioengineering 2015. 
** This recent study demonstrates high titers of $\beta$ ketoadipate and muconolactone from protocatechuate in an engineered strain of Pseudomonas putida KT2440.

Lupoi JS, Singh S, Parthasarathi R, Simmons BA, Henry RJ: Recent innovations in analytical methods for the qualitative and quantitative assessment of lignin. Renewable and Sustainable Energy Reviews 2015, 49:871906.

** This paper gives a comprehensive review of techniques available to probe the chemical structure of the lignin polymer within a feedstock.

\section{References}

1. Ralph J: Hydroxycinnamates in lignification. Phytochemistry Reviews 2010, 9:65-83.

2. Chen F, Tobimatsu Y, Havkin-Frenkel D, Dixon RA, Ralph $\mathrm{J}$ : A polymer of caffeyl alcohol in plant seeds. Proceedings of the National Academy of Sciences 2012, 109:1772-1777.

3. Bonawitz ND, Im Kim J, Tobimatsu Y, Ciesielski PN, Anderson NA, Ximenes E, Maeda J, Ralph J, Donohoe BS, Ladisch M: Disruption of Mediator rescues the stunted growth of a lignin-deficient Arabidopsis mutant. Nature 2014, 509:376-380.

4. Wagner A, Tobimatsu Y, Phillips L, Flint H, Geddes B, Lu $F$, Ralph J: Syringyl lignin production in conifers: Proof of concept in a Pine tracheary element system. Proceedings of the National Academy of Sciences 2015, 112:6218-6223.

5. Wilkerson C, Mansfield S, Lu F, Withers S, Park J-Y, Karlen S, Gonzales-Vigil E, Padmakshan D, Unda F, Rencoret J, et al.: Monolignol ferulate transferase introduces chemically labile linkages into the lignin backbone. Science 2014, 344:90-93.

6. Eudes A, Sathitsuksanoh N, Baidoo EE, George A, Liang $Y$, Yang F, Singh S, Keasling JD, Simmons BA, Loqué D: Expression of a bacterial 3 - dehydroshikimate dehydratase reduces lignin content and improves biomass saccharification efficiency. Plant Biotechnology Journal 2014.

7. Davis R, Tao L, Tan E, Biddy MJ, Beckham GT, Scarlata C, Jacobson J, Cafferty K, Ross J, Lukas J, et al.: Process Design and Economics for the Conversion of Lignocellulosic Biomass to Hydrocarbons: Dilute-Acid Prehydrolysis and Enzymatic Hydrolysis Deconstruction of Biomass to Sugars and Biological Conversion of Sugars to Hydrocarbons. Edited by Laboratory NRE. Golden, CO: NREL; 2013.

8. Ragauskas AJ, Beckham GT, Biddy MJ, Chandra R, Chen F, Davis MF, Davison BH, Dixon RA, Gilna P, Keller M, et al.: Lignin Valorization: Improving Lignin Processing in the Biorefinery. Science 2014, 344:1246843.
9. Zakzeski J, Bruijnincx PCA, Jongerius AL, Weckhuysen BM: The Catalytic Valorization of Lignin for the Production of Renewable Chemicals. Chemical Reviews 2010, 110:3552-3599.

10. Martínez ÁT, Speranza M, Ruiz-Dueñas FJ, Ferreira $P$, Camarero $S$, Guillén F, Martínez MJ, Gutiérrez A, del Río JC: Biodegradation of lignocellulosics: microbial, chemical, and enzymatic aspects of the fungal attack of lignin. International Microbiology 2010, 8:195-204.

11. Fuchs $G$, Boll $M$, Heider J: Microbial degradation of aromatic compounds - from one strategy to four. Nature Reviews Microbiology 2011, 9:803-816.

12. Boll M, Löffler C, Morris BE, Kung JW: Anaerobic degradation of homocyclic aromatic compounds via arylcarboxyl - coenzyme A esters: organisms, strategies and key enzymes. Environmental Microbiology 2014, 16:612-627.

13. Bugg TDH, Rahmanpour R: Enzymatic conversion of lignin into renewable chemicals. Current Opinion in Chemical Biology 2015, 29:10-17.

14. Chundawat SPS, Beckham, G.T., Himmel, M.E., and Dale, B. E.: Deconstruction of lignocellulosic biomass to fuels and chemicals. Ann. Rev. Chem. Biomolec. Eng. 2011, 2:121-145.

15. George A, Brandt A, Tran K, Zahari SMNS, KleinMarcuschamer D, Sun N, Sathitsuksanoh N, Shi J, Stavila V, Parthasarathi R: Design of low-cost ionic liquids for lignocellulosic biomass pretreatment. Green Chemistry 2015, 17:1728-1734.

16. Socha AM, Parthasarathi R, Shi J, Pattathil S, Whyte D, Bergeron M, George A, Tran K, Stavila V, Venkatachalam S: Efficient biomass pretreatment using ionic liquids derived from lignin and hemicellulose. Proceedings of the National Academy of Sciences 2014, 111:E3587-E3595.

17. Song Q, Wang F, Cai J, Wang Y, Zhang J, Yu W, Xu J: Lignin depolymerization (LDP) in alcohol over nickelbased catalysts via a fragmentation-hydrogenolysis process. Energy \& Environmental Science 2013, 6:994-1007.

18. Ferrini $P$, Rinaldi R: Catalytic Biorefining of Plant Biomass to Non - Pyrolytic Lignin Bio - Oil and Carbohydrates through Hydrogen Transfer Reactions. Angewandte Chemie International Edition 2014, 53:8634-8639.

19. Van den Bosch $S$, Schutyser W, Vanholme R, Driessen T, Koelewijn S-F, Renders T, De Meester B, Huijgen W, Dehaen W, Courtin C: Reductive lignocellulose fractionation into soluble lignin-derived phenolic monomers and dimers and processable carbohydrate pulps. Energy \& Environmental Science 2015.

20. Parsell T, Yohe S, Degenstein J, Jarrell T, Klein I, Gencer E, Hewetson B, Hurt M, Im Kim J, Choudhari H: A synergistic biorefinery based on catalytic conversion of lignin prior to cellulose starting from 
lignocellulosic biomass. Green Chemistry 2015, 17:1492-1499.

21. Luo H, Klein IM, Jiang $Y$, Zhu H, Liu B, Kenttamaa HI, Abu-Omar MM: Total Utilization of Miscanthus Biomass, Lignin and Carbohydrates, Using Earth Abundant Nickel Catalyst. ACS Sustainable Chemistry \& Engineering 2016.

22. Chen XW, Tao L, Shekiro J, Mohaghaghi A, Decker S, Wang W, Smith $\mathrm{H}$, Park S, Himmel ME, Tucker M: Improved ethanol yield and reduced Minimum Ethanol Selling Price (MESP) by modifying low severity dilute acid pretreatment with deacetylation and mechanical refining: 1) Experimental. Biotechnology for Biofuels 2012, 5.

23. Karp EM, Donohoe BS, O'Brien MH, Ciesielski PN, Mittal A, Biddy MJ, Beckham GT: Alkaline pretreatment of corn stover: Bench-scale fractionation and stream characterization ACS Sust. Chem. Eng 2014, 2:1481-1491.

24. Karp EM, Resch MG, Donohoe BS, Ciesielski PN, O’Brien MH, Nill JE, Mittal A, Biddy MJ, Beckham GT: Alkaline Pretreatment of Switchgrass. ACS Sustainable Chemistry \& Engineering 2015, 3:14791491.

25. Linger JG, Vardon DR, Guarnieri MG, Karp EM, Hunsinger GB, Franden MA, Johnson CW, Chupka G, Strathmann TJ, Pienkos PT, et al.: Lignin valorization through integrated biological funneling and chemical catalysis. Proc. Natl. Acad. Sci. 2014, 111:1201312018.

26. Li C, Zhao X, Wang A, Huber GW, Zhang T: Catalytic Transformation of Lignin for the Production of Chemicals and Fuels. Chemical Reviews 2015, 115:11559-11624.

27. Ma $R$, Xu Y, Zhang $X$ : Catalytic Oxidation of Biorefinery Lignin to Value - added Chemicals to Support Sustainable Biofuel Production. ChemSusChem 2015, 8:24-51.

28. Vardon DR, Franden MA, Johnson CW, Karp EM, Guarnieri MT, Linger JG, Salm MJ, Strathmann TJ, Beckham GT: Adipic acid production from lignin. Energy \& Environmental Science 2015, 8:617-628.

29. Johnson CW, Beckham GT: Aromatic catabolic pathway selection for optimal production of pyruvate and lactate from lignin. Metabolic Engineering 2015, 28:240-247.

30. Salvachúa D, Karp EM, Nimlos CT, Vardon DR, Beckham GT: Towards lignin consolidated bioprocessing: simultaneous lignin depolymerization and product generation by bacteria. Green Chemistry 2015, 17:4951-4967.

31. McLeod MP, Warren RL, Hsiao WWL, Araki N, Myhre $M$, Fernandes C, Miyazawa $D$, Wong $W$, Lillquist $A L$, Wang D, et al.: The complete genome of Rhodococcus sp. RHA1 provides insights into a catabolic powerhouse. Proceedings of the National Academy of Sciences 2006, 103:15582-15587.

32. Kosa M, Ragauskas AJ: Lignin to lipid bioconversion by oleaginous Rhodococci. Green Chemistry 2013, 15:2070-2074.

33. Barbe $V$, Vallenet $D$, Fonknechten $N$, Kreimeyer $A$, Oztas S, Labarre L, Cruveiller S, Robert C, Duprat S, Wincker $P$, et al.: Unique features revealed by the genome sequence of Acinetobacter sp. ADP1, a versatile and naturally transformation competent bacterium. Nucleic Acids Research 2004, 32:57665779.

34. Masai E, Katayama Y, Fukuda M: Genetic and biochemical investigations on bacterial catabolic pathways for lignin-derived aromatic compounds. Bioscience, Biotechnology, and Biochemistry 2007, 71:1-15.

35. Masai E, Katayama Y, Nishikawa S, Fukuda M: Characterization of Sphingomonas paucimobilis SYK6 genes involved in degradation of lignin-related compounds. Journal of Industrial Microbiology and Biotechnology 1999, 23:364-373.

36. Masai E, Kamimura N, Kasai D, Oguchi A, Ankai A, Fukui S, Takahashi M, Yashiro I, Sasaki H, Harada T: Complete genome sequence of Sphingobium sp. strain SYK-6, a degrader of lignin-derived biaryls and monoaryls. Journal of Bacteriology 2012, 194:534535.

37. Camarero $S$, Martínez $M$, Martínez A: Lignindegrading enzymes produced by Pleurotus species during solid state fermentation of wheat straw. In Advances in Solid State Fermentation. Edited by: Springer; 1997:335-345.

38. Camarero S, Martínez MJ, Martínez AT: Understanding lignin biodegradation for the improved utilization of plant biomass in modern biorefineries. Biofuels, Bioproducts and Biorefining 2014, 8:615-625.

39. Nikel PI, Martínez-García E, de Lorenzo V: Biotechnological domestication of pseudomonads using synthetic biology. Nature Reviews Microbiology 2014, 12:368-379.

40. Martínez-García E, Nikel PI, Aparicio T, de Lorenzo V: Pseudomonas 2.0: genetic upgrading of $P$. putida KT2440 as an enhanced host for heterologous gene expression. Microb Cell Fact 2014, 13:159.

41. Lieder S, Nikel PI, de Lorenzo V, Takors R: Genome reduction boosts heterologous gene expression in Pseudomonas putida. Microbial Cell Factories 2015, 14:23.

42. Fernández $H$, Prandoni $N$, Fernández-Pascual $M$, Fajardo S, Morcillo C, Díaz E, Carmona M: Azoarcus sp. CIB, an anaerobic biodegrader of aromatic compounds shows an endophytic lifestyle. PloS one 2014, 9:e110771. 
43. Heider J, Boll M, Breese K, Breinig S, Ebenau-Jehle C, Feil U, Gad'on N, Laempe D, Leuthner B, Mohamed ME-S: Differential induction of enzymes involved in anaerobic metabolism of aromatic compounds in the denitrifying bacterium Thauera aromatica. Archives of microbiology 1998, 170:120-131.

44. Trautwein K, Grundmann O, Wöhlbrand L, Eberlein C, Boll $M$, Rabus R: Benzoate mediates repression of C4-dicarboxylate utilization in "Aromatoleum aromaticum" EbN1. Journal of bacteriology 2012, 194:518-528.

45. Billings AF, Fortney JL, Hazen TC, Simmons $B$, Davenport KW, Goodwin L, Ivanova N, Kyrpides NC, Mavromatis K, Woyke T: Genome sequence and description of the anaerobic lignin-degrading bacterium Tolumonas lignolytica sp. nov. Standards in Genomic Sciences 2015, 10.

46. Woo HL, Ballor NR, Hazen TC, Fortney JL, Simmons B, Davenport KW, Goodwin L, Ivanova N, Kyrpides NC, Mavromatis K: Complete genome sequence of the lignin-degrading bacterium Klebsiella sp. strain BRL6-2. Stand. Genomic Sci 2014, 9:19.

47. DeAngelis KM, Sharma $D$, Varney $R$, Simmons $B$, Isern NG, Markilllie LM, Nicora C, Norbeck AD, Taylor RC, Aldrich JT: Evidence supporting dissimilatory and assimilatory lignin degradation in Enterobacter lignolyticus SCF1. Frontiers in Microbiology 2013, 4.

48. Bugg TD, Ahmad M, Hardiman EM, Singh R: The emerging role for bacteria in lignin degradation and bio-product formation. Current Opinion in Biotechnology 2011, 22:394-400.

49. Bugg TD, Ahmad M, Hardiman EM, Rahmanpour R: Pathways for degradation of lignin in bacteria and fungi. Natural Product Reports 2011, 28:1883-1896.

50. Roberts JN, Singh R, Grigg JC, Murphy ME, Bugg TD, Eltis LD: Characterization of dye-decolorizing peroxidases from Rhodococcus jostii RHA1. Biochemistry 2011, 50:5108-5119.

51. Ahmad M, Roberts JN, Hardiman EM, Singh R, Eltis LD, Bugg TDH: Identification of DypB from Rhodococcus jostii RHA1 as a Lignin Peroxidase. Biochemistry 2011, 50:5096-5107.

52. Santos A, Mendes S, Brissos V, Martins LO: New dyedecolorizing peroxidases from Bacillus subtilis and Pseudomonas putida MET94: towards biotechnological applications. Applied Microbiology and Biotechnology 2014, 98:2053-2065.

53. Brown ME, Barros $\mathrm{T}$, Chang MC: Identification and characterization of a multifunctional dye peroxidase from a lignin-reactive bacterium. ACS Chemical Biology 2012, 7:2074-2081.

54. Hullo M-F, Moszer I, Danchin A, Martin-Verstraete I: CotA of Bacillus subtilis is a copper-dependent laccase. Journal of Bacteriology 2001, 183:5426-5430.

55. Picart $P$, de María PD, Schallmey A: From gene to biorefinery: microbial $\beta$-etherases as promising biocatalysts for lignin valorization. Frontiers in Microbiology 2015, 6.

56. Strachan $C R$, Singh $R$, Vanlnsberghe $D$, levdokymenko K, Budwill K, Mohn WW, Eltis LD, Hallam SJ: Metagenomic scaffolds enable combinatorial lignin transformation. Proceedings of the National Academy of Sciences 2014, 111:10143-10148.

57. Armstrong Z, Mewis K, Strachan C, Hallam SJ: Biocatalysts for biomass deconstruction from environmental genomics. Current Opinion in Chemical Biology 2015, 29:18-25.

58. Chung D, Cha M, Guss AM, Westpheling J: Direct conversion of plant biomass to ethanol by engineered Caldicellulosiruptor bescii. Proceedings of the National Academy of Sciences 2014:201402210.

59. Lynd LR, Van Zyl WH, McBRIDE JE, Laser M: Consolidated bioprocessing of cellulosic biomass: an update. Current Opinion in Biotechnology 2005, 16:577-583.

60. Zhao C, Xie S, Pu Y, Zhang R, Huang F, Ragauskas AJ, Yuan JS: Synergistic enzymatic and microbial lignin conversion. Green Chemistry 2015.

61. Payne CM, Knott BC, Mayes HB, Hansson H, Himmel ME, Sandgren M, Ståhlberg J, Beckham GT: Fungal Cellulases. Chemical Reviews 2015, 115:1308-1448.

62. Salvachúa $D$, Prieto $A$, Mattinen M-L, Tamminen $T$, Liitiä T, Lille M, Willför S, Martínez AT, Martínez MJ, Faulds CB: Versatile peroxidase as a valuable tool for generating new biomolecules by homogeneous and heterogeneous cross-linking. Enzyme and Microbial Technology 2013, 52:303-311.

63. Harwood CS, Nichols NN, Kim M-K, Ditty JL, Parales RE: Identification of the pcaRKF gene cluster from Pseudomonas putida: involvement in chemotaxis, biodegradation, and transport of 4hydroxybenzoate. Journal of Bacteriology 1994, 176:6479-6488.

64. Nichols NN, Harwood CS: PcaK, a high-affinity permease for the aromatic compounds 4hydroxybenzoate and protocatechuate from Pseudomonas putida. Journal of Bacteriology 1997, 179:5056-5061.

65. Xu Y, Wang S-H, Chao H-J, Liu S-J, Zhou N-Y: Biochemical and Molecular Characterization of the Gentisate Transporter GenK in Corynebacterium glutamicum. PLOS ONE 2012, 7:e38701.

66. Michalska K, Chang C, Mack JC, Zerbs S, Joachimiak A, Collart FR: Characterization of Transport Proteins for Aromatic Compounds Derived from Lignin: Benzoate Derivative Binding Proteins. Journal of Molecular Biology 2012, 423:555-575.

67. Otani H, Lee $Y-E$, Casabon I, Eltis LD: Characterization of p-Hydroxycinnamate Catabolism in a Soil Actinobacterium. Journal of Bacteriology 2014, 196:4293-4303. 
68. Jiménez Jl, Miñambres B, Garcia JL, Díaz E: Genomic analysis of the aromatic catabolic pathways from Pseudomonas putida KT2440. Environmental Microbiology 2002, 4:824-841.

69. Nordlund I, Powlowski J, Shingler V: Complete nucleotide sequence and polypeptide analysis of multicomponent phenol hydroxylase from Pseudomonas sp. strain CF600. Journal of bacteriology 1990, 172:6826-6833.

70. Nurk A, Kasak L, Kivisaar M: Sequence of the gene (pheA) encoding phenol monooxygenase from Pseudomonas sp. EST1001: expression in Escherichia coli and Pseudomonas putida. Gene 1991, 102:13-18.

71. Saa L, Jaureguibeitia A, Largo E, Llama MJ, Serra JL: Cloning, purification and characterization of two components of phenol hydroxylase from Rhodococcus erythropolis UPV-1. Applied microbiology and biotechnology 2010, 86:201-211.

72. Dardas A, Gal D, Barrelle M, Sauret-Ignazi G, Sterjiades $\mathrm{R}$, Pelmont J: The demethylation of guaiacol by a new bacterial cytochrome P-450. Archives of Biochemistry and Biophysics 1985, 236:585-592.

73. Eltis LD, Karlson $U$, Timmis KN: Purification and characterization of cytochrome P450RR1 from Rhodococcus rhodochrous. European Journal of Biochemistry 1993, 213:211-216.

74. Kawahara N, Ikatsu H, Kawata H, Miyoshi S-i, Tomochika K-i, Sinoda S: Purification and characterization of 2-ethoxyphenol-induced cytochrome P450 from Corynebacterium sp. strain EP1. Canadian Journal of Microbiology 1999, 45:833839.

75. Camarero S, Ibarra D, Martínez MJ, Martínez ÁT: Lignin-derived compounds as efficient laccase mediators for decolorization of different types of recalcitrant dyes. Applied and environmental microbiology 2005, 71:1775-1784.

76. Sainsbury PD, Hardiman EM, Ahmad M, Otani $H$, Seghezzi N, Eltis LD, Bugg TDH: Breaking Down Lignin to High-Value Chemicals: The Conversion of Lignocellulose to Vanillin in a Gene Deletion Mutant of Rhodococcus jostii RHA1. ACS Chemical Biology 2013, 8:2151-2156.

77. Thompson B, Machas $M$, Nielsen DR: Creating pathways towards aromatic building blocks and fine chemicals. Current Opinion in Biotechnology 2015, 36:1-7.

78. Vaillancourt FH, Bolin JT, Eltis LD: The ins and outs of ring-cleaving dioxygenases. Critical Reviews in Biochemistry and Molecular Biology 2006, 41:241267.

79. Bugg TD: Dioxygenase enzymes: catalytic mechanisms and chemical models. Tetrahedron 2003, 59:7075-7101.

80. Schlosrich J, Eley KL, Crowley PJ, Bugg TD: Directed Evolution of a Non - Heme - Iron - Dependent
Extradiol Catechol Dioxygenase: Identification of Mutants with Intradiol Oxidative Cleavage Activity. Chembiochem 2006, 7:1899-1908.

81. Barry KP, Cohn EF, Ngu A, Taylor EA: Improving alternate lignin catabolite utilization of LigAB from Sphingobium sp. strain SYK-6 through site directed mutagenesis. Process Biochemistry 2015, 50:16341639.

82. Barry KP, Taylor EA: Characterizing the promiscuity of LigAB, a lignin catabolite degrading extradiol dioxygenase from Sphingomonas paucimobilis SYK6. Biochemistry 2013, 52:6724-6736.

83. Han L, Liu P, Sun J, Wu Y, Zhang Y, Chen W, Lin J, Wang $Q$, Ma Y: Engineering catechol 1, 2-dioxygenase by design for improving the performance of the cis, cismuconic acid synthetic pathway in Escherichia coli. Scientific reports 2015, 5.

84. Matera I, Ferraroni M, Kolomytseva M, Golovleva L, Scozzafava A, Briganti F: Catechol 1, 2-dioxygenase from the Gram-positive Rhodococcus opacus 1CP: quantitative structure/activity relationship and the crystal structures of native enzyme and catechols adducts. Journal of structural biology 2010, 170:548564.

85. Barry KP, Ngu A, Cohn EF, Cote JM, Burroughs AM, Gerbino JP, Taylor EA: Exploring allosteric activation of LigAB from Sphingobium sp. strain SYK-6 through kinetics, mutagenesis and computational studies. Archives of biochemistry and biophysics 2015, 567:3545.

86. Sugimoto K, Senda M, Kasai D, Fukuda M, Masai E, Senda T: Molecular Mechanism of Strict Substrate Specificity of an Extradiol Dioxygenase, DesB, Derived from Sphingobium sp. SYK-6. PLOS ONE 2014, 9:e92249.

87. Draths KM, Frost JW: Environmentally compatible synthesis of adipic acid from D-glucose. J. Amer. Chem. Soc. 1994, 116:399-400.

88. Polen T, Spelberg M, Bott M: Toward biotechnological production of adipic acid and precursors from biorenewables. Journal of Biotechnology 2013, 167:75-84.

89. Curran KA, Leavitt JM, Karim AS, Alper HS: Metabolic engineering of muconic acid production in Saccharomyces cerevisiae. Metabolic Engineering 2013, 15:55-66.

90. Sonoki T, Morooka M, Sakamoto K, Otsuka Y, Nakamura M, Jellison J, Goodell B: Enhancement of protocatechuate decarboxylase activity for the effective production of muconate from ligninrelated aromatic compounds. Journal of Biotechnology 2014, 192:71-77.

91. Weber C, Brückner C, Weinreb S, Lehr C, Essl C, Boles $\mathrm{E}$ : Biosynthesis of cis, cis-muconic acid and its aromatic precursors, catechol and protocatechuic acid, from renewable feedstocks by Saccharomyces 
cerevisiae. Applied and Environmental Microbiology 2012, 78:8421-8430.

92. Michinobu T, Hishida M, Sato M, Katayama $Y$, Masai E, Nakamura $M$, Otsuka $Y$, Ohara $S$, Shigehara K: Polyesters of 2-pyrone-4, 6-dicarboxylic acid (PDC) obtained from a metabolic intermediate of lignin. Polymer Journal 2008, 40:68-75.

93. Hishida M, Shikinaka K, Katayama Y, Kajita S, Masai E, Nakamura $M$, Otsuka $Y$, Ohara $S$, Shigehara K: Polyesters of 2-Pyrone-4,6-dicarboxylic Acid (PDC) as Bio-based Plastics Exhibiting Strong Adhering Properties. Polym. J 2009, 41:297-302.

94. Mycroft Z, Gomis M, Mines P, Law P, Bugg TD: Biocatalytic conversion of lignin to aromatic dicarboxylic acids in Rhodococcus jostii RHA1 by rerouting aromatic degradation pathways. Green Chemistry 2015, 17:4974-4979.

95. Okamura-Abe $Y$, Abe T, Nishimura K, Kawata $Y$, SatoIzawa K, Otsuka Y, Nakamura M, Kajita S, Masai E, Sonoki T: Beta-ketoadipic acid and muconolactone production from a lignin-related aromatic compound through the protocatechuate 3, 4metabolic pathway. Journal of Bioscience and Bioengineering 2015.

96. Asano Y, Yamamoto Y, Yamada H: Catechol 2, 3dioxygenase-catalyzed synthesis of picolinic acids from catechols. Bioscience, Biotechnology, and Biochemistry 1994, 58:2054-2056.

97. Gosling A, Fowler SJ, O'Shea MS, Straffon M, Dumsday $G$, Zachariou M: Metabolic production of a novel polymer feedstock, 3-carboxy muconate, from vanillin. Applied microbiology and biotechnology 2011, 90:107-116.

98. Peralta-Yahya PP, Zhang FZ, del Cardayre SB, Keasling JD: Microbial engineering for the production of advanced biofuels. Nature 2012, 488:320-328.

99. van Duuren JB, Wijte D, Karge B, Martins dos Santos $V A$, Yang $Y$, Mars AE, Eggink G: pH - stat fed - batch process to enhance the production of cis, cis muconate from benzoate by Pseudomonas putida KT2440 - JD1. Biotechnology Progress 2012, 28:8592.

100. del Castillo T, Ramos JL: Simultaneous catabolite repression between glucose and toluene metabolism in Pseudomonas putida is channeled through different signaling pathways. Journal of bacteriology 2007, 189:6602-6610.

101. Xie N-Z, Liang $H$, Huang R-B, Xu P: Biotechnological production of muconic acid: current status and future prospects. Biotechnology Advances 2014, 32:615-622.

102. Bang S-G, Choi CY: DO-stat fed-batch production of cis, cis-muconic acid from benzoic acid by Pseudomonas putida BM014. Journal of Fermentation and Bioengineering 1995, 79:381-383.
103. Madkour MH, Heinrich D, Alghamdi MA, Shabbaj II, Steinbüchel A: PHA recovery from biomass. Biomacromolecules 2013, 14:2963-2972.

104. Ramaswamy S, Huang H-J, Ramarao BV: Separation and purification technologies in biorefineries: John Wiley \& Sons; 2013.

105. Heeres AS, Picone CS, van der Wielen LA, Cunha RL, Cuellar MC: Microbial advanced biofuels production: overcoming emulsification challenges for large-scale operation. Trends in Biotechnology 2014, 32:221-229.

106. Lu R, Lu F, Chen J, Yu W, Huang Q, Zhang J, Xu J: Production of Diethyl Terephthalate from Biomass Derived Muconic Acid. Angewandte Chemie 2015.

107. Gallezot P: Conversion of biomass to selected chemical products. Chemical Society Reviews 2012, 41:1538-1558.

108. Sheldon RA: Green and sustainable manufacture of chemicals from biomass: state of the art. Green Chemistry 2014, 16:950-963.

109. Wettstein SG, Alonso DM, Gürbüz El, Dumesic JA: A roadmap for conversion of lignocellulosic biomass to chemicals and fuels. Current Opinion in Chemical Engineering 2012, 1:218-224.

110. Schwartz TJ, O'Neill BJ, Shanks BH, Dumesic JA: Bridging the chemical and biological catalysis gap: challenges and outlooks for producing sustainable chemicals. ACS Catalysis 2014, 4:2060-2069.

111. Kumar $P$, Barrett DM, Delwiche MJ, Stroeve $P$ : Methods for pretreatment of lignocellulosic biomass for efficient hydrolysis and biofuel production. Industrial \& Engineering Chemistry Research 2009, 48:3713-3729.

112. Menon V, Rao $M$ : Trends in bioconversion of lignocellulose: biofuels, platform chemicals \& biorefinery concept. Progress in Energy and Combustion Science 2012, 38:522-550.

113. Baucher M, Halpin C, Petit-Conil M, Boerjan W: Lignin: genetic engineering and impact on pulping. Critical Reviews in Biochemistry and Molecular Biology 2003, 38:305-350.

114. Vanholme R, Morreel K, Ralph J, Boerjan W: Lignin engineering. Current Opinion in Plant Biology 2008, 11:278-285.

115. Chen F, Dixon RA: Lignin modification improves fermentable sugar yields for biofuel production. Nature Biotechnology 2007, 25:759-761.

116. Weng J-K, Li X, Bonawitz ND, Chapple C: Emerging strategies of lignin engineering and degradation for cellulosic biofuel production. Current Opinion in Biotechnology 2008, 19:166-172.

117. Chen F, Tobimatsu Y, Jackson L, Nakashima J, Ralph J, Dixon RA: Novel seed coat lignins in the Cactaceae: structure, distribution and implications for the evolution of lignin diversity. The Plant Journal 2013, 73:201-211. 
118. Heitner C, Dimmel D, Schmidt J: Lignin and lignans: advances in chemistry: CRC press; 2010.

119. Lupoi JS, Singh S, Parthasarathi R, Simmons BA, Henry RJ: Recent innovations in analytical methods for the qualitative and quantitative assessment of lignin. Renewable and Sustainable Energy Reviews 2015, 49:871-906.

120. Niemelä K, Sjöström E: Simultaneous identification of aromatic and aliphatic low molecular weight compounds from alkaline pulping liquor by capillary gas-liquid chromatography-mass spectrometry. Holzforschung 1986, 40:361-368.

121. Kuban P, Karlberg B: On-line monitoring of kraft pulping liquors with a valveless flow injectioncapillary electrophoresis system. Analytica Chimica Acta 2000, 404:19-28.

122. Volgger D, Zemann A, Bonn G: Determination of phenols, inorganic anions, and carboxylic acids in Kraft black liquors by capillary electrophoresis. Journal of High Resolution Chromatography 1998, 21:3-10.

123. Shackman JG, Munson MS, Ross D: Gradient elution moving boundary electrophoresis for highthroughput multiplexed microfluidic devices. Analytical Chemistry 2007, 79:565-571.

124. Strychalski EA, Henry AC, Ross D: Microfluidic analysis of complex samples with minimal sample preparation using gradient elution moving boundary electrophoresis. Analytical Chemistry 2009, 81:10201-10207. 
Graphical Abstract

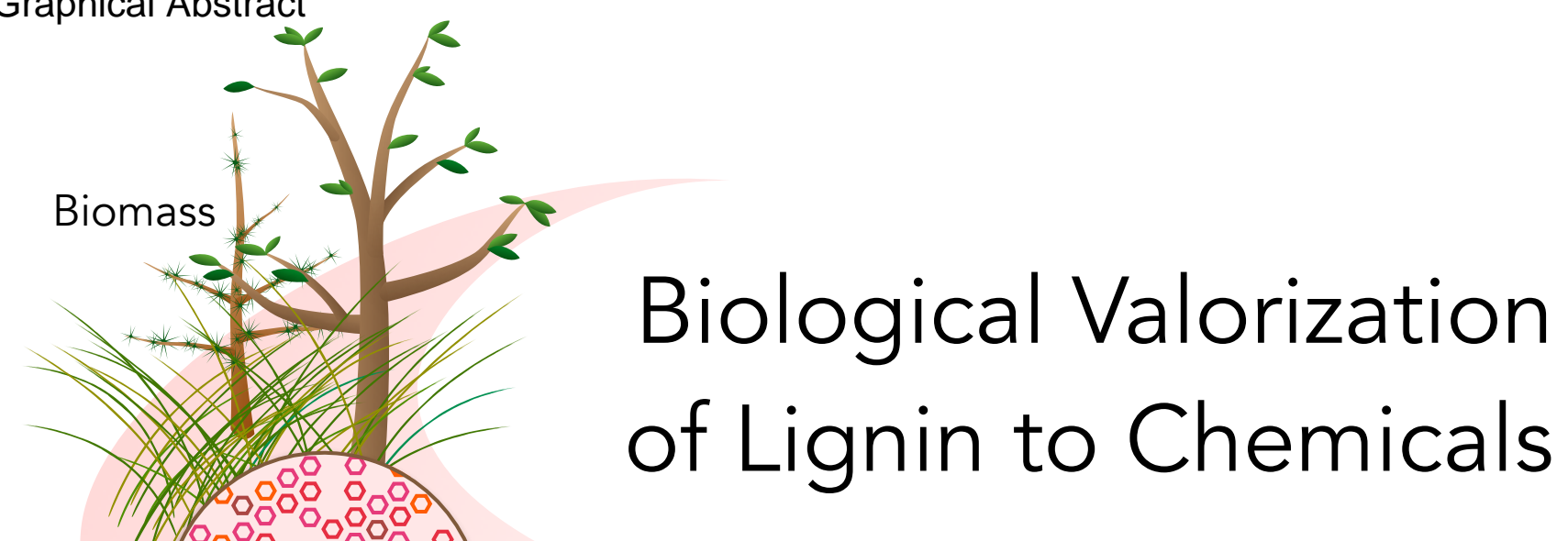

Lignin

Deconstruction 6

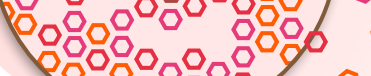

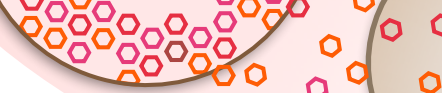

0 0

Microbial

Conversion

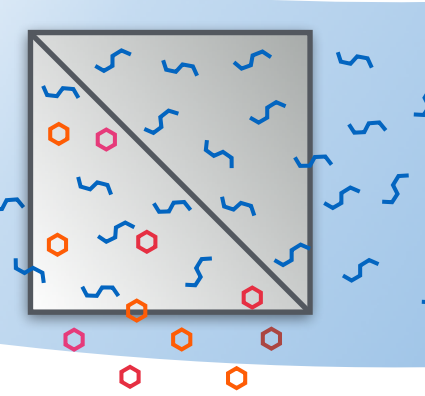

Separations

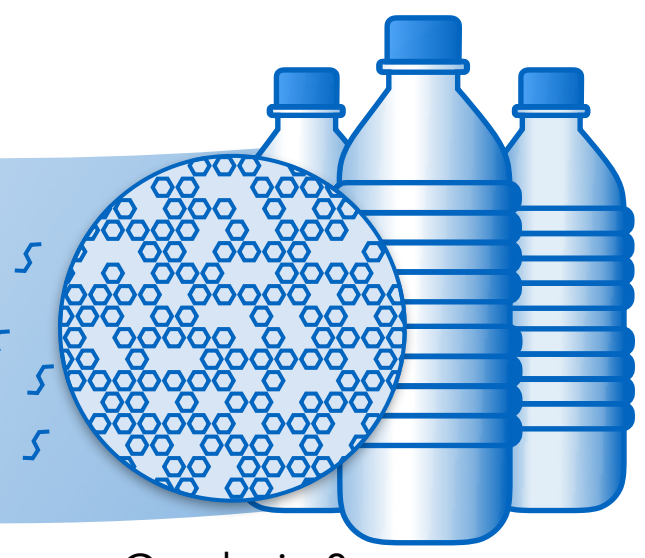

Catalysis \&

Polymerization 